\title{
О ВЛИЯНИИ ИНГИБИТОРОВ НАТРИЙ-ГЛЮКОЗНОГО КОТРАНСПОРТЕРА 2 НА СОСТОЯНИЕ МИТОХОНДРИЙ И АКТИВНОСТЬ АУТОФАГИИ
}

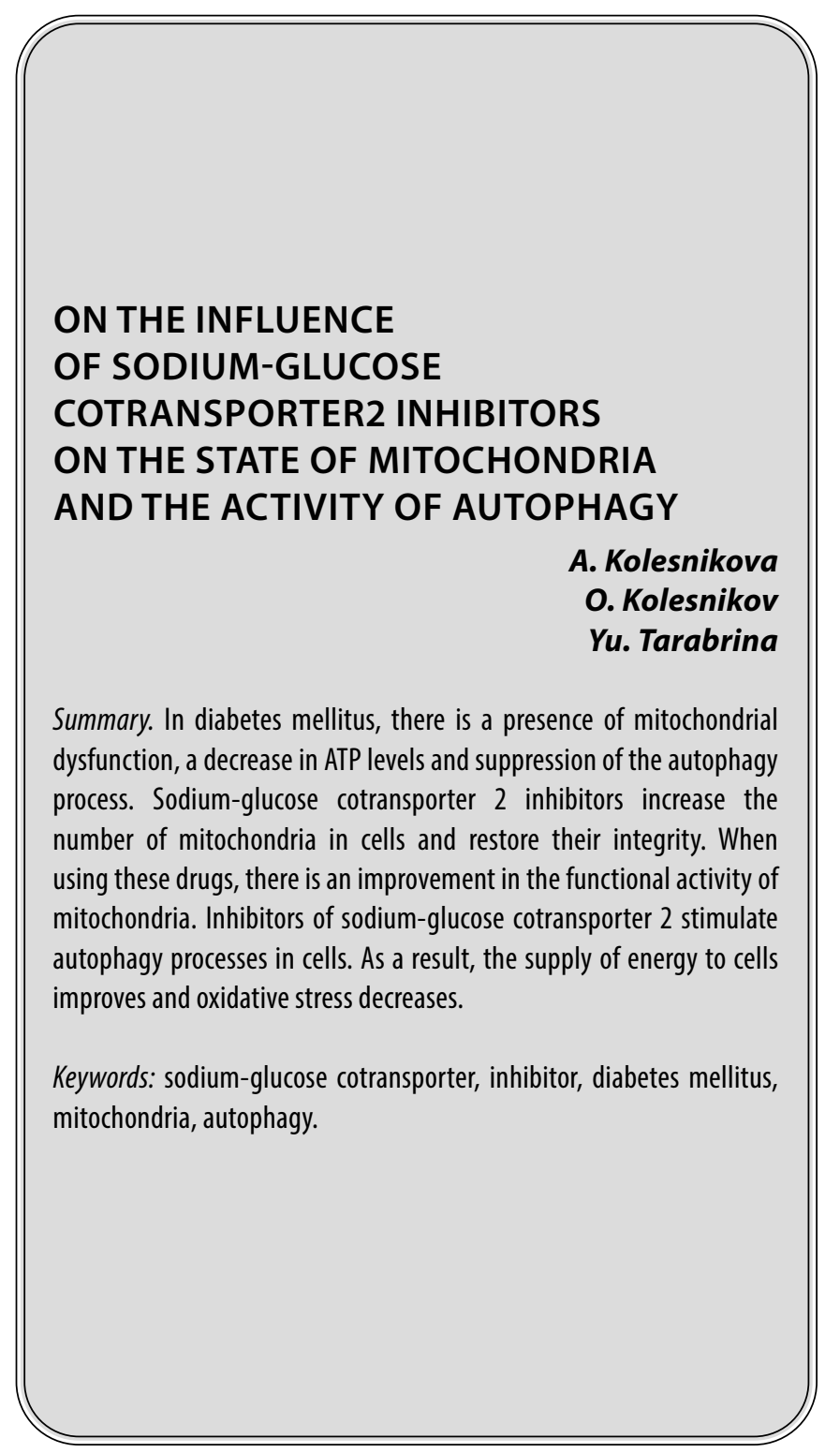

U нгибиторы натрий-глюкозного котранспортера 2 типа (ИНГК2) сегодня активно используются в лечении сахарного диабета $[1,2]$. Первый ингибитор натрий-глюкозного котранспортера флоризин (подавляет активность котранспортеров 1 и 2 типов) был выделен в 1835 году и является первым представителем данного класса, который был одобрен в США Food and Drug Administration для лечения сахарного диабета [3].
Колесникова Алла Алексеевна

К.м.н., дочент, ФГБОУ ВО «Южно-Уральский государственный медицинский университет» Минздрава России (2. Челябинск) olekol@mail.ru

Колесников Олег Леонидович Д.м.н., профрессор, ФГБОУ ВО «Южно-Уральский государственный медицинский университет» Минздрава России (2. Челябинск) kaf-biol@mail.ru

Тарабрина Юлия Олеговна

К.м.н., доцент, ФГБОУ ВО «Южно-Уральский государственный медицинский университет» Минздрава России (г. Челябинск) julikol@mail.ru

Аннотация. При сахарном диабете отмечается наличие дисфункции митохондрий, снижение уровня АТФ и подавление процесса аутофагии. Ингибиторы натрий-глюкозного котранспортера 2 увеличивают количество митохондрий в клетках и восстанавливают их целостность. При использовании этих препаратов отмечается улучшение функциональной активности митохондрий. Ингибиторы натрий-глюкозного котранспортера 2 стимулируют процессы аутофагии в клетках. В результате улучшается снабжение клеток энергией и уменьшается оксидативный стресс.

Ключевые слова: натрий-глюкозный котранспортер, ингибитор, сахарный диабет, митохондрия, аутофагия.

В исследованиях сердечно-сосудистых исходов, наблюдающихся при использовании ИНГК2, было зарегистрировано либо меньшее количество серьезных неблагоприятных сердечных событий (нефатальный инфаркт миокарда, нефатальный инсульт и сердечно-сосудистая смерть), либо снижение совокупной конечной точки сердечно-сосудистой смерти или госпитализации по поводу сердечной недостаточности $(\mathrm{CH})$ у участников с сахарным диабетом 2 типа (СД2) и уста- 
новленным сердечно-сосудистым заболеванием. Среди пациентов с СД2, у которых не было сердечно-сосудистых заболеваний, но имелись множественные факторы риска, ИНГК2 снижали комбинированную конечную точку сердечно-сосудистой смерти или госпитализации по причине $\mathrm{CH}[4,5,6]$.

Вопрос о механизмах кардиопротекторного действия ИНГК2 активно изучается, существует целый ряд гипотез по этому поводу. При этом весьма важно, что сам белок (натрий-глюкозный котранспортер 2 типа) в кардиомиоцитах не экспрессируется, в тканях сердца был обнаружен только натрий-глюкозный котранспортер 1 типа $[7,8]$.

Настоящее сообщение посвящено анализу данных литературы о воздействии ИНГК2 состояние митохондрий.

Миокард требует большого количества энергии для обеспечения своей работы. Большая часть этой энергии вырабатывается в результате окислительного фосфорилирования в митохондриях, которые составляют около 30\% объема миокарда. Митохондрии также являются основным источником активных форм кислорода (АФК), которые образуются из цепи переноса электронов во время окислительного фосфорилирования [9]. В физиологических условиях повреждение миокарда, вызванное АФК, сводится к минимуму благодаря жесткому контролю окислительно-восстановительного баланса митохондрий и эффективной и динамичной программе контроля качества митохондрий. Контроль качества митохондрий обеспечивает пригодность популяции митохондрий посредством непрерывных проверок качества, устранения дисфункциональных митохондрий и стимулирования роста новых органелл [10].

СД2 характеризуется митохондриальной дисфункцией, высокой выработкой активных форм кислорода и низким уровнем АТФ [11].

Дисфункция митохондрий была обнаружена во многих органах у пациентов с СД2 [12]. Так, митохондрии, выделенные из предсердий людей с СД, демонстрировали сниженное митоходриальное дыхание и увеличенный оксидативный стресс по сравнению с митохондриями здоровых людей [13]. При СД2 наблюдается сниженная экспрессия генов, вовлеченных в биогенез митохондрий и окислительное фосфорилирование [14]. Исследования у пациентов с СД2 связали митохондриальную дисфункцию с гипертрофией и фиброзом желудочков $[15,16]$.

Белки Drp1 и Mfn1 связаны с делением митохондрий, а высокое соотношение Drp1/Mfn1 отражает увеличенную фрагментацию митохондрий [17].
Lee Y.H. и соавт. (2019) использовали культуру клеток проксимальных почечных канальцев человека, которые инкубировали при повышенной концентрации глюкозы. После воздействия эмпаглифлозина соотношение Drp1/ Mfn1 снижалось, что позволяет думать об уменьшении фрагментации митохондрий [18]. С помощью MitoTracker, который окрашивал функционирующие митохондрии с неповрежденным мембранным потенциалом, было показано, что при высоком уровне глюкозы в клетках уменьшалось количество функциональных митохондрий. При обработке эмпаглифлозином восстанавливалась масса нормально функционирующих митохондрий. Кроме того, ИНГК2 восстанавливал базальное митохондриальное дыхание. Авторы указали, что эмпаглифлозин улучшал динамику, биогенез и функции митохондрий в клетках при инкубации в среде с высоким содержанием глюкозы [18]. Другие исследователи показали, что эмпаглифлозин ингибировал деление митохондрий через активацию АМФ-зависимой протеинкиназы [19].

В работе Takagi S. и соавт. (2018) изучали линию эпителиальных клеток HK-2. Инкубация клеток в среде с пальмитатом снизила экспрессию белков митохондрий Mfn2 и Ора1, в присутствии ИНГК2 этот эффект не отмечался. При использовании среды с пальмитатом и высоким уровнем глюкозы наблюдалось значительное разрушение митохондрий. ИНГК2 ипраглифлозин восстанавливал экспрессию митохондрий [20].

Целый ряд исследований проведен с помощью различных моделей СД и ожирения. Так, крыс линии Вистар содержали на диете с высоким содержанием жиров, часть из них получала дапаглифлозин. ИНГК2 улучшал чувствительность животных к инсулину, функции митохондрий головного мозга, уменьшал апоптоз и предотвратил снижение когнитивных функций [21].

Wei D. и соавт. (2020) также использовали высоко жировую диету. У самцов мышей C57BL/6 обнаружили снижение уровня мРНК и экспрессии белков PGC-1a, NRF1, tfam и CPT1b, которые являются маркерами митохондриального биогенеза, функций и окисления жирных кислот. ИНГК2 канаглифлозин отменял эти эффекты. Кроме того, адипоциты линии 3T3-L1 обрабатывали канаглифлозином, который усиливал экспрессию белков PGC-1a, NRF1, tfam, COX5b, СРT1b. Следовательно, ИНГК2 улучшал функцию митохондрий и улучшал окисление жирных кислот [22].

В следующем исследовании мыши в течение 16 недель содержались на диете с высоким содержанием жира и получали ИНГК2 ипраглифлозин. У животных в клетках канальцев почек обнаружены округлые и фрагментированные митохондрии, также характерно было нарушение внутренней мембраны. Ипраглифло- 
зин уменьшал повреждения митохондрий. Авторы указали, что при дисфункции митохондрий могут усиливаться гликолиз и оксидативный стресс [20].

Mizuno M. и соавт. (2018) использовали крыс линии OLETF (модель СД2) и линии LETO (недиабетический контроль). Для индукции инфаркта миокарда перевязывали левую коронарную артерию и через 12 часов забирали образцы из зоны, не пораженной инфарктом. У крыс с СД2 было больше митохондрий, и были более распространены мелкие митохондрии, чем у линии LETO. Инфаркт миокарда при СД2 еще больше сокращал размер митохондрий и уменьшал число аутофагических вакуолей. ИНГК2 эмпаглифлозин предотвращал сокращение размеров митохондрий и числа аутофагических вакуолей после инфаркта у крыс с СД2. Авторы указали, что ИНГК2 нормализует количество и размер митохондрий при СД2 [23].

Belosludtsev K.N. и соавт. (2021) изучали мышей линии C57BL/6NCrl, у которых вызывали СД2 с помощью стрептозоцина и диеты с высоким содержанием жира. С помощью электронной микроскопии изучали клетки печени. Дапаглифлозин предотвращал набухание митохондрий и нормализовал средний размер митохондрий в гепатоцитах животных с СД2. Лечение ИНГК2 предотвращало снижение числа копий митохондриальной ДНК в печени мышей с диабетом. Дапаглифлозин у животных с СД2 нормализовал соотношение митохондриального респираторного контроля, и достоверно уменьшил уровень продуктов перекисного окисления липидов в митохондриях [24]. Есть и другие данные, согласно которым ингибиторы НГК2 могут улучшать дыхательную функцию митохондрий у диабетических крыс [25]

Теперь перейдем к рассмотрению такого важного вопроса, как аутофагия.

Аутофагия - это эволюционно консервативный процесс, который опосредует клеточную адаптацию к стрессовым условиям, и представляет собой процесс деградации клеточных элементов с помощью лизосом [26]. Аутофагия помогает избавить клетки от накопленного «мусора», избыточных запасов глюкозы и липидов и дисфункциональных или поврежденных органелл, которые способствуют развитию заболеваний [27]. В связи с этим она имеет важнейшее значение для гомеостаза, развития и выживания клеток [28]. В условиях стресса аутофагия играет особо важную роль, устраняя поврежденные или вредные компоненты [29]. Нарушение аутофагии может быть частью патогенеза многих заболеваний, включая нейродегенеративные, сердечно-сосудистые, аутоиммунные и метаболические [27].

Таким образом, аутофагия поддерживает функционирование органоидов клетки (в том числе и мито- хондрий), обеспечивая своевременное удаление поврежденных структур. Говоря о митохондриях, следует не забывать, что удаление неполноценных, дефектных структур позволяет снизить утечку активных форм кислорода и уменьшает уровень оксидативного стресса в клетке. Как же обстоят дела с аутофагией при сахарном диабете?

В условиях гипергликемии процессы аутофагии могут нарушаться [30]. При СД2 отмечается подавление аутофагии, что способствует развитию кардиомиопатии [31]. В клетках людей с СД2 способность к аутофагии заметно снижается [32, 33].

Подавление аутофагии связано с гипергликемией, накоплением конечных гликированных продуктов и липидов в связи с дефицитом глюкозы и угнетением окисления жирных кислот [34].

Ряд регуляторных ферментов, в том числе сиртуин-1 (СИРТ-1) и АМФ-активируемая протеинкиназа (АМФПК) обеспечивают активацию аутофагии, причем при СД2 отмечается супрессия как СИРТ-1, так и АМФПК. [31].

Недостаток питательных веществ увеличивает экспрессию и активность ряда регуляторных энзимов, в частности СИРТ-1 и АМФПК [35]. ИНГК2 вызывают состояние, подобное голоданию, которое сопровождается кетогенезом, являющимся биомаркером активации СИРТ-1 [31].

ИНГК2 обеспечивают активацию СИРТ-1 в различных тканях, включая почки $[36,37,38]$. При этом есть данные, что ИНГК2 могут прямо влиять на СИРТ-1, повышая его активность [37].

Таким образом, отмечаемая при использовании ИНГК2 стимуляция аутофагии может вносить вклад в поддержание структуры и функциональной активности митохондрий, способствуя снабжению клеток АТФ и уменьшая оксидативный стресс.

\section{Зак^ючение}

Сахарный диабет нарушает снабжение клеток энергией, отмечается нарушение функций и целостности митохондрий. Это вызывает подавление синтеза АТФ и активирует оксидативный стресс. Кроме того, при СД2 нарушается аутофагия, которая обеспечивает своевременное удаление из клеток поврежденных органоидов и молекул. ИНГК2 обеспечивают стимуляцию аутофагии через активацию СИРТ-1. В результате восстанавливается активность митохондрий и снабжение клеток АТФ. Эти особенности могут вносить вклад в кардиопротекторное и ренопротекторное действие ИНГК2. 


\section{ЛИТЕРАТУРА}

1. Garcia-Ropero A. The pharmacokinetics and pharmacodynamics of SGLT2 inhibitors for type 2 diabetes mellitus: the latest developments / A. Garcia-Ropero, J.J. Badimon, C.G. Santos-Gallego // Expert. Opin. Drug. Metab. Toxicol._ 2018. Vol. 14, N12.—P. 1287-1302. D0I: 10.1080/17425255.2018.1551877.

2. Rosas-Guzman J. SGLT2 Inhibitors in Diabetes Mellitus Treatment / J. Rosas-Guzman, J. Rosas-Saucedo, A.R.J. Romero-Garcia // Rev. Recent. Clin. Trials. 2017.—Vol. 12, N1. — P. 8-18. D0I: 10.2174/1574887111666160829145810.

3. Perry R.J. Sodium-glucose cotransporter-2 inhibitors: Understanding the mechanisms for therapeutic promise and persisting risks / R.J. Perry, G.I. Shulman // J. Biol. Chem. - 2020. - Vol. 295, Is. 42. - P. 14379-14390.

4. Woo V.C. Cardiovascular Effects of Sodium-Glucose Cotransporter-2 Inhibitors in Adults With Type 2 Diabetes / V.C. Woo // Can. J. Diabetes. — 2020. — Vol. 44, N1. - P. 61-67. D0I: 10.1016/j.jcjd.2019.09.004.

5. Zelniker T.A. SGLT2 inhibitors for primary and secondary prevention of cardiovascular and renal outcomes in type 2 diabetes: a systematic review and metaanalysis of cardiovascular outcome trials / T.A. Zelniker, S.D. Wiviott, I. Raz [et al.] // Lancet. — 2019. — Vol. 393.— P. 31-39.

6. Toyama T. Effect of SGLT2 inhibitors on cardiovascular, renal and safety outcomes in patients with type 2 diabetes mellitus and chronic kidney disease: a systematic review and meta-analysis / T. Toyama, B.L. Neuen, M. Jun [et al.] // Diabetes Obes. Metabol. — 2019._ Vol. 21.—P. 1237-1250.

7. Maejima Y. SGLT2 Inhibitors Play a Salutary Role in Heart Failure via Modulation of the Mitochondrial Function / Y. Maejima // Front. Cardiovasc. Med. 2020. — Vol. 6. — Article ID: 186. DOl: 10.3389/fcvm.2019.00186.

8. Di Franco A. Sodium-dependent glucose transporters (SGLT) in human ischemic heart: a new potential pharmacological target / A. Di Franco, G. Cantini, A. Tani [et al.] / Int. J. Cardiol.— 2017.—Vol. 243.—P. 86-90. D0l: 10.1016/j.ijcard.2017.05.032.

9. Yurista S.R. Sodium-glucose co-transporter 2 inhibition as a mitochondrial therapy for atrial fibrillation in patients with diabetes? / S.R. Yurista, H.H.W. Silljé, M. Rienstra [et al.] // Cardiovasc. Diabetol. — 2020.—Vol. 19, N1.—Article ID: 5. D0I: 10.1186/s12933-019-0984-0.

10. Brown D.A. Mitochondrial function as a therapeutic target in heart failure / D.A. Brown, J.B. Perry, M.E. Allen [et al.] // Nat. Rev. Cardiol. - 2017.— Vol. 14, N4. - P. 238-250. D0I: 10.1038/nrcardio.2016.203.

11. Rovira-Llopis S. Mitochondrial dynamics in type 2 diabetes: Pathophysiological implications / S. Rovira-Llopis, C. Bañuls, N. Diaz-Morales [et al.] // Redox. Biol.— 2017.—Vol. 11.—P. 637-645. D0l: 10.1016/j.redox.2017.01.013.

12. Yaribeygi H. Mitochondrial dysfunction in diabetes and the regulatory roles of antidiabetic agents on the mitochondrial function / H. Yaribeygi, S.L. Atkin, A. Sahebkar // J. Cell. Physiol. — 2019.— Vol. 234, N6.—P. 8402-8410. D0l: 10.1002/jcp. 27754.

13. Anderson E.J. Substrate-specific derangements in mitochondrial metabolism and redox balance in the atrium of the type 2 diabetic human heart / E.J. Anderson, A.P. Kypson, E. Rodriguez [et al.] // J. Am. Coll. Cardiol. — 2009. — Vol. 54, N20.—P. 1891-1898. D0I: 10.1016/j.jacc.2009.07.031.

14. Mootha V.K. PGC-1alpha-responsive genes involved in oxidative phosphorylation are coordinately downregulated in human diabetes / V.K. Mootha, C.M. Lindgren, K.F. Eriksson [et al.] // Nat. Genet. — 2003._ Vol. 34, N3. P. 267-273. D0I: 10.1038/ng1180.

15. Montaigne $D$. Myocardial contractile dysfunction is associated with impaired mitochondrial function and dynamics in type 2 diabetic but not in obese patients / D. Montaigne, X. Marechal, A. Coisne [et al.] // Circulation. - 2014. — Vol. 130. — P. 554-64.

16. Uthman L. Direct cardiac actions of sodium glucose cotransporter 2 inhibitors target pathogenic mechanisms underlying heart failure in diabetic patients / L. Uthman, A. Baartscheer, C.A. Schumacher [et al.] // Front. Physiol. — 2018.—Vol. 9. — Article ID:1575.

17. Jeong H.Y. Chloroquine and amodiaquine enhance AMPK phosphorylation and improve mitochondrial fragmentation in diabetic tubulopathy / H.Y. Jeong, J.M. Kang, H.H. Jun [et al.] // Sci. Rep. — 2018. — Vol. 8. — Article ID: 8774. D0I:10.1038/s41598-018-26858-8.

18. Lee Y.H. Empagliflozin attenuates diabetic tubulopathy by improving mitochondrial fragmentation and autophagy / Y.H. Lee, S.H. Kim, J.M. Kang [et al.] // Am.J. Physiol. Renal Physiol. — 2019. — Vol. 317, N4. — P. F767-F780. D0I: 10.1152/ajprenal.00565.2018.

19. Zhou H. Empagliflozin rescues diabetic myocardial microvascular injury via AMPK-mediated inhibition of mitochondrial fission / H. Zhou, S. Wang, P. Zhu // Redox. Biol.—2018. — Vol. 15.—P. 335-346. D0I: 10.1016/j.redox.2017.12.019.

20. Takagi S. Ipragliflozin improves mitochondrial abnormalities in renal tubules induced by a high-fat diet / S. Takagi, J. Li, Y. Takagaki [et al.] // J. Diabetes Investig. — 2018. - Vol. 9, N5.—P. 1025-1032. D0I: 10.1111/jdi.12802.

21. Sa-Nguanmoo P. SGLT2-inhibitor and DPP-4 inhibitor improve brain function via attenuating mitochondrial dysfunction, insulin resistance, inflammation, and apoptosis in HFD-induced obese rats / P. Sa-Nguanmo0, P. Tanajak, S. Kerdphoo [et al.] // Toxicol. Appl. Pharmacol.— 2017.—Vol. 333.— P. 43-50. D0l: 10.1016/j.taap.2017.08.005.

22. Wei D. Canagliflozin ameliorates obesity by improving mitochondrial function and fatty acid oxidation via PPARa in vivo and in vitro / D. Wei, L. Liao, H. Wang // Life Sci. — 2020. — Vol. 247.—Article ID: 117414. D0l: 10.1016/j.lfs.2020.117414.

23. Mizuno M. Empagliflozin normalizes the size and number of mitochondria and prevents reduction in mitochondrial size after myocardial infarction in diabetic hearts / M. Mizuno, A. Kuno, T. Yano [et al.] // Physiol. Rep. — 2018. — Vol. 6, N12.—Article ID: e13741. D0I: 10.14814/phy2.13741.

24. Belosludtsev K.N. Chronic treatment with dapagliflozin protects against mitochondrial dysfunction in the liver of C57BL/6NCrl mice with high-fat diet/ streptozotocin-induced diabetes mellitus / K.N. Belosludtsev, V.S. Starinets, M.N. Belosludtsev [et al.] // Mitochondrion. — 2021.—Vol. 59. — P. 246-254. DOl: 10.1016/j.mito.2021.06.008.

25. Shao Q. Empagliflozin, a sodium glucose co-transporter-2 inhibitor, alleviates atrial remodeling and improves mitochondrial function in high-fat diet/ streptozotocin-induced diabetic rats / Q. Shao, L. Meng, S. Lee [et al.] // Cardiovasc. Diabetol. — 2019.—Vol. 18, N1.—Article ID: 165. D0I: 10.1186/s12933019-0964-4. 
26. Demirtas L. Apoptosis, autophagy \& endoplasmic reticulum stress in diabetes mellitus / L. Demirtas, A. Guclu, F.M. Erdur [et al.] // Indian J. Med. Res. 2016. - Vol. 144, N4.—P. 515-524. D01: 10.4103/0971-5916.200887.

27. Levine B. Development of autophagy inducers in clinical medicine / B. Levine, M. Packer, P. Codogno // J. Clin. Invest. — 2015. — Vol. 125, N1. — P. 14-24. DOI: $10.1172 / \mathrm{JCI} 33938$.

28. Levine B. Autophagy in the pathogenesis of disease / Levine B, Kroemer G. // Cell. — 2008.—Vol. 132, N1. — P. 27-42. D0l: doi: 10.1016/j.cell.2007.12.018.

29. He C. Regulation mechanisms and signaling pathways of autophagy / C. He, D.J. Klionsky // Annu. Rev. Genet.— 2009.—Vol. 43.—P. 67-93. D0l: 10.1146/ annurev-genet-102808-114910.

30. Tanaka Y. Autophagy as a therapeutic target in diabetic nephropathy / Tanaka Y., Kume S., Kitada M. [et al.] // Exp. Diabetes Res. — 2012.— Vol. 2012. Article ID: 628978. D0I: 10.1155/2012/628978.

31. Packer M. Autophagy-dependent and -independent modulation of oxidative and organellar stress in the diabetic heart by glucose-lowering drugs / M. Packer // Cardiovasc. Diabetol. - 2020.—Vol. 19, N1. — Article ID: 62. D0I: 10.1186/s12933-020-01041-4.

32. Sakai S. Proximal tubule autophagy differs in type 1 and 2 diabetes / S. Sakai, T. Yamamoto, Y. Takabatake [et al.] // J. Am. Soc. Nephrol. - 2019.— Vol. 30, N6. - P. 929-945. DOI: 10.1681/ASN.2018100983.

33. Zhao X. Advanced glycation end-products suppress autophagic flux in podocytes by activating mammalian target of rapamycin and inhibiting nuclear translocation of transcription factor EB / X. Zhao, Y. Chen, X. Tan [et al.] // J. Pathol._ 2018. — Vol. 245, N2. - P. 235-248. D0I: 10.1002/path.5077.

34. Kang H.M. Defective fatty acid oxidation in renal tubular epithelial cells has a key role in kidney fibrosis development / H.M. Kang, S.H. Ahn, P. Choi [et al.] // Nat. Med. - 2015.—Vol. 21, N1. - P. 37-46. D0l: 10.1038/nm.3762.

35. Panieri E. Nutrient withdrawal rescues growth factor-deprived cells from mTOR-dependent damage / E. Panieri, G. Toietta, M. Mele [et al.] // Aging (Albany NY).— 2010.—Vol. 2, N8.—P. 487-503. D0l: 10.18632/aging.100183.

36. Sasaki M. Dual regulation of gluconeogenesis by insulin and glucose in the proximal tubules of the kidney / M. Sasaki, T. Sasako, N. Kubota [et al.] // Diabetes. 2017. - Vol. 66, N9._P. 2339-2350. D0I: 10.2337/db16-1602.

37. Ying Y. Phloretin protects against cardiac damage and remodeling via restoring SIRT1 and anti-inflammatory effects in the streptozotocin-induced diabetic mouse model / Y. Ying, C. Jiang, M. Zhang [et al.] // Aging (Albany NY). — 2019._-Vol. 11, N9. — P. 2822-2835. D0I: 10.18632/aging.101954.

38. Kim J.W. Effect of sodium-glucose cotransporter 2 inhibitor, empagliflozin, and a-glucosidase inhibitor, voglibose, on hepatic steatosis in an animal model of type 2 diabetes / J.W. Kim, Y.J. Lee, Y.H. You [et al.] // J. Cell Biochem. — 2019. — Vol. 120, Is. 5. — P. 8534-854. D0l: 10.1002/jcb.28141. 